\title{
Evaluation of infertile women by diagnostic hysterolaparoscopy
}

\author{
Sujata N Datti, Shruthi K, Shreedhar Venkatesh, Nagatejaswi T, Ravi Sree Shivani
}

Corresponding author: Dr. Shruthi K, 902 A block, Mahaveer Tranquil Apartments, Whitefield, Bengaluru, Karnataka, 560066, India; Email : shrukalagara@gmail.com

Distributed under Attribution-Non Commercial - Share Alike 4.0 International (CC BY-NC-SA 4.0)

\begin{abstract}
Objectives: The objectives of the study are to identify the causes of infertility on diagnostic hysterolaparoscopy (DHL) and its correlation with infertility. Methods: This is a retrospective study of infertile women who underwent DHL in a tertiary care hospital during January to December 2019. The medical records of 120 women who underwent DHL during the study period were analyzed. The intraoperative findings were noted. The causes of infertility were assessed. Results: Among 120 women who underwent DHL $92(77.31 \%)$ had primary infertility and $28(22.69 \%)$ had secondary infertility. 44 women were in age group of 26-30y (36.66\%). On Hysteroscopy, 104 (86.66\%) cases had normal finding. Most common abnormal hysteroscopy finding was uterine polyp in 8(6.66\%) women. On laparoscopy, 49(40.83\%) women had normal findings. Tubal block being the most common pathology noted in 31 cases $(25.83 \%)$ in which bilateral block was found in $16(13.33 \%)$ and unilateral block in $15(12.5 \%)$, followed by PID in $15(12.5 \%)$. 36 procedures were carried out in the same setting including ovarian drilling in $14(11.66 \%)$, ovarian cystectomy in $8(6.66 \%)$, laparoscopic adhesiolysis in $4(3.33 \%)$, hysteroscopic polypectomy in $8(6.66 \%)$ and hysteroscopic septal resection in $2(1.66 \%)$. Conclusion: DHL is a very useful tool for infertility evaluation. It helps in decision making and can help couples looking at a last resort for natural conception since therapeutic procedures could be performed if required.
\end{abstract}

Keywords: Female infertility, hysteroscopy, laparoscopy.

Infertility is defined as the inability of a couple to achieve conception after one year of unprotected coitus. In general, the prevalence of infertility is estimated to be $10-15 \%$ among young couples. ${ }^{1}$ According to World Health Organization (WHO), the term primary infertility is used when a women has never conceived and secondary infertility is the inability to conceive in a couple who have had at least one successful conception in the past. $^{2}$

The main causes of infertility include disorders of ovulation (30-40\%), tubal and peritoneal factors (30-40\%), male factor $(20 \%)$, cervical factors $(5 \%)$, uterine factor (15\%), unexplained infertility $(10 \%) .^{3} \quad$ Diagnostic hysterolaparoscopy (DHL) is the most important diagnostic procedure for the detection of causes of infertility. Laparoscopy helps in identification of possible pelvic pathology and hysteroscopy helps in visualizing the uterine cavity and identifying the possible pathology. DHL also provides the clinician an opportunity for therapeutic procedure at the time of diagnosis. The study was done to identify the causes of infertility on DHL and correlation with demographic profile in a tertiary care hospital, in South India.

\section{Materials and methods}

This was a retrospective observational study conducted in tertiary care hospital during January to December 2019. All patients with complaints of infertility (primary and secondary) who underwent DHL in OBG department of a tertiary care centre during the study period with normal semen analysis were included. Patient's data was retrieved from the medical department after obtaining institutional

Received: $9^{\text {th }}$ January 2021, Peer review completed: $25^{\text {th }}$ February 2021, Accepted: $7^{\text {th }}$ March 2021.

Datti SN, Shruthi K, Venkatesh S, Nagatejaswi T, Shivani RS. Evaluation of infertile women by diagnostic hysterolaparoscopy. The New Indian Journal of OBGYN. 2022; 8(2): 295 - 98. 
The New Indian Journal of OBGYN. 2021 (January-June);8(2)

ethical committee clearance.

The data collected were demographic factors such as age, duration and type of infertility, base line hormonal profile and semen analysis report. Diagnostic hysterolaparoscopy was performed under general anaesthesia. Data regarding adhesions and features suggestive of endometriosis, adenomyosis, and fibroids; ovarian, fallopian tubes and culde-sac abnormalities was retrieved from the case sheets. Hysteroscopic findings, chromopertubation details and therapeutic procedures done at the same setting were noted.

Statistical analysis: Data was entered in MS Excel spreadsheet. Categorical variables presented in numbers and percentage and continuous variables as mean.

\section{Results}

One hundred and twenty patients underwent DHL for infertility during the period of one year. Among 120 women, 92(77.31\%) had primary infertility and 28(22.69\%) had secondary infertility including 20 women with previous miscarriage and 8 women with previous live birth.

Table 1: Age distribution of patients

\begin{tabular}{lll}
\hline Age in years & $\mathbf{N}(\mathbf{1 2 0})$ & Percentage $\mathbf{( \% )}$ \\
\hline $20-25$ & 40 & 33.33 \\
$26-30$ & 44 & 36.66 \\
$31-35$ & 28 & 23.33 \\
$36-40$ & 7 & 5.83 \\
$>40$ & 1 & 0.83 \\
\hline
\end{tabular}

The patient's age distribution was between $18-38$ years. Majority of the cases 44 (36.66\%), were between age group of 26-30 years followed by 40 cases $(33.33 \%)$ between the age group of $20-25 y e a r s, 28$ cases $(23.33 \%)$ belong to the age group of $31-35 y e a r s, 7 \operatorname{cases}(5.83 \%)$ belong to the age group of 36-40 years, and one belong to $>40$ years $(0.8 \%)$ (table 1). 62 women presented with complaints of failure to conceive within 5 yrs of married life (51.66\%), 47 (39.16\%) presented between 5-10 yrs of married life and 11 (9.16\%) after 10 years of married life. On hysteroscopy, 104 $(86.66 \%)$ patients had normal finding, $8(6.66 \%)$ had polyps, $6(5 \%)$ had septate uterus followed by synechiae in $2(1.66 \%)$ (table 2).

Table 2: Hysteroscopic findings

\begin{tabular}{lll}
\hline Hysteroscopy findings & N (120) & Percentage (\%) \\
\hline Normal & 104 & 86.66 \\
Polyp & 8 & 6.66 \\
Septate uterus & 6 & 5 \\
Synechiae & 2 & 1.66 \\
\hline
\end{tabular}

On laparoscopy, 49 (40.83\%) had normal findings. Tubal block was the most common pathology noted in 31cases $(25.83 \%)$, in which bilateral block was found in $16(13.33 \%)$ and unilateral block in 15 (12.5\%), followed by PID in 15 $(12.5 \%)$, ovarian cysts in $14(11.66 \%)$, endometriosis in 8
(6.66\%), fibroids were noted in 5(4.16\%) and arcuate uterus in $1(0.83 \%)$ (table 3$)$.

Table 3: Laparoscopy findings

\begin{tabular}{lll}
\hline Laparoscopy findings & N (120) & Percentage (\%) \\
\hline Normal & 49 & 40.83 \\
Tubal block & 31 & 25.83 \\
Bilateral & 16 & 13.33 \\
Unilateral & 15 & 12.5 \\
PID & 15 & 12.5 \\
Ovarian cysts & 14 & 11.66 \\
Endometriosis & 8 & 6.66 \\
Fibroid & 5 & 4.16 \\
Arcuate uterus & 1 & 0.83 \\
\hline PID - Pelvic inflammatory disease &
\end{tabular}

PID - Pelvic inflammatory disease

36 procedures were carried out in the same setting including ovarian drilling in 14 (11.66\%), ovarian cystectomy in $8(6.66 \%)$, laparoscopic adhesiolysis in 4 (3.33\%), hysteroscopic polypectomy in $8(6.66 \%)$ and hysteroscopic septal resection in $2(1.66 \%)$ (table 4$)$.

\section{Table 4: Procedure done}

\begin{tabular}{l|ll}
\hline Procedure done & Total & Percentage \\
\hline Ovarian drilling & 14 & 11.66 \\
Ovarian cystectomy & 8 & 6.66 \\
Laparoscopic adhesiolysis & 4 & 3.33 \\
Hysteroscopic polypectomy & 8 & 6.66 \\
Hysteroscopic septal resection & 2 & 1.66 \\
\hline
\end{tabular}

\section{Discussion}

Infertility is a distressing condition which negatively affects the quality of couple's life. Identification of the cause for infertility could relieve the stress associated with infertility work-up. Hence DHL could help in identifying the cause for female infertility and early referral for artificial reproductive techniques (ART), if required.

According to WHO the overall prevalence of primary infertility in India is between 3.9 to $16.8 \%$ and prevalence varies from state to state. ${ }^{2}$ In our study of 120 women who underwent DHL during the study period, 92(77.31\%) presented with primary infertility and 28(22.69\%) with secondary infertility. Primary infertility was found to be more common. Similar to a study by Manisha Shrivastava et al $2019,{ }^{1}$ among 205 infertile women, there were $127(61.95 \%)$ cases with primary infertility and $78(38.05 \%)$ with secondary infertility. Similarly in a study by YM Kabadi, B Harsha ${ }^{4}$, among 94 cases, 50 cases (53.1\%) had primary infertility, $16(17.1 \%)$ had secondary infertility. In this study only 8 women with secondary infertility had a previous live birth. 20 women with secondary infertility presented with history of previous miscarriage.

In our study 44 women were in the age group 26-30 yrs (36.66\%). Similarly in a study by YM Kabadi, B Harsha ${ }^{4}$, 31 cases $(33 \%)$ were in the age group of 26-30 years and in a study by Manisha Shrivastava et $\mathrm{al}^{1}$, among primary 
infertility cases $41.73 \%$ were between 26 - 36 years of age whereas the majority $(42.31 \%)$ of patients in secondary infertility group were in 31- 35 years of age group. This clustering around 26 to 30 years could be explained by later age at marriage, greater interest in higher education and careers resulting in delayed childbearing.

In our study 62 women presented with complaints of failure to conceive within 5 yrs of married life (51.66\%), 47 (39.16\%) presented between 5-10yrs of married life and 11 $(9.16 \%)$ after 10 years of married life. Whereas in a study by YM Kabadi, B Harsha ${ }^{4}, 45$ (47.8 \%) had a married life of 510 years. Delayed childbearing after marriage is considered by many couples either for education or career, thanks to advances in contraception. Creating awareness among couples about age related decline in fertility should always be considered.

In our study 104 cases $(86.66 \%)$ had normal findings on hysteroscopy. The commonest uterine abnormality was polyps $(6.66 \%)$, followed by uterine septum $(5 \%)$ and synechiae (2\%). Whereas a study by YM Kabadi, B Harsha ${ }^{4}$ shows that the incidence of uterine anomaly was $13(13.8 \%)$ and in a study by Godinjak $\mathrm{Z}$ et al, septate uterus (37.15\%) was the most common uterine anomaly followed by bicornuate uterus $(26.13 \%)$ in infertile couple. ${ }^{5}$ Mehta AV et al ${ }^{6}$ stated that the most common intrauterine pathology in primary and secondary infertility group was uterine septum. Similar to our study the most common intrauterine pathology was uterine polyps $(47.89 \%$ in primary infertility group; $29.51 \%$ in secondary infertility group) in a study by Zhang $\mathrm{E}$ et al ${ }^{7}$. In a study by Dhananjaya Shobha et al ${ }^{8}$ the commonest hysteroscopic uterine cavity abnormality in primary and secondary infertility was endometrial polyp seen in $10.13 \%$ and $19.05 \%$ of the women respectively.

Endometrial polyp size and associated symptoms would determine the treatment plan, but there is sufficient evidence that polypectomy improves reproductive performance. Uterine septum and other uterine anomalies have been associated with pregnancy loss, but association with infertility is still debatable. Uterine anomalies could be considered an obstacle for planning treatment.

On laparoscopy 49 cases (40.83\%) in our study had normal findings, which is similar to other studies. ${ }^{4,9}$ Among abnormal findings include 31 cases (25.83\%) with tubal block followed by PID in 15 (12.25\%), ovarian cysts in 14 $(11.66 \%)$, endometriosis in $8(6.66 \%)$, fibroid uterus in 5 $(4.16 \%)$ and arcuate uterus in $1(0.83 \%)$. Similarly in a study by Manisha Shrivastava et al ${ }^{1}$, the most common pathology was PID (16.8\%). In a study by Suman Puri et $\mathrm{al}^{10}, 50$ women were included and tubal block was noted in $18 \%$. In our study tubal block (25.83\%) followed by PID (12.25\%) were the commonest abnormal findings on Laparoscopy. The tubal damage resulting in block could be a consequence of PID.

In our study 36 procedures were carried out in the same setting including ovarian drilling in $14(11.66 \%)$, ovarian cystectomy in $8(6.66 \%)$, laparoscopic adhesiolysis in 4 (3.33\%), hysteroscopic polypectomy in $8(6.66 \%)$ and hysteroscopic septal resection in $2(1.66 \%)$. Performing therapeutic procedure lies in the expertise of the operator, availability of resources and the importance of patient consent has to be considered. Hence this study demonstrates the usefulness of DHL as a diagnostic and therapeutic option for women with infertility, providing evidence for decision between surgery and ART.

\section{Conclusion}

DHL is a very useful tool for infertility evaluation. It also helps to treat various pelvic pathologies in the same setting. DHL is a safe procedure in skilled hands and provides vital information regarding causes of infertility. It can be used as one step option prior to in-vitro fertilization, especially in couples who want to know the cause for infertility. It helps in decision making and in planning further management of women with infertility. It can help couples looking at a last resort for natural conception since therapeutic procedures could be performed if required.

\section{Conflict of interest: None. Disclaimer: Nil.}

\section{References}

1. Shrivastava M, Meena BS. Study of Role of Combined Diagnostic Hysteroscopy and Laparoscopy in Evaluating Factors for Infertility. JMSCR. 2019; 7(1): 803-7.

2. Rutstein SO, Shah IH. Infecundity, Infertility, and Childlessness in Developing Countries. DHS Comparative Reports No. 9. Calverton, Maryland, USA: ORC Macro and the World Health Organization. 2004.

3. Thimmappa SS, Datti SN. Diagnostic laparoscopy in evaluation of female subfertility factors: experience in rural medical college. International Journal of Contemporary Medical Research. 2020; 7(3): C1-C4.

4. Kabadi YM, Harsha B. Hysterolaparoscopy in the Evaluation and Management of Female Infertility. J Obstet Gynaecol India. 2016; 66(Suppl 1): 478-481.

5. Godinjak Z, Idrizbegovic E. Should diagnostic hysteroscopy be a routine procedure during diagnostic 
The New Indian Journal of OBGYN. 2021 (January-June);8(2)

laparoscopy in infertile women? Bosn J Basic Med. 2008; 8: 44-7.

6. Mehta AV, Modi AP, Raval BM, Munshi SP. Role of diagnostic hysterolaparoscopy in the evaluation of infertility. Int J Reprod Contracept Obstet Gynecol. 2016 Feb; 5(2): 437-40.

7. Zhang E, Zhang Y, Fang L, Li Q, Gu J. Combined Hysterolaparoscopy for the Diagnosis of Female Infertility: a Retrospective Study of 132 Patients in China. Materia Socio Medica. 2014; 26(3):156.

8. Shobha D, Madhu KN, Agrawal A. Role of Diagnostic Hysterolaparoscopy in Evaluation of Primary and Secondary Infertility. Journal of Evolution of Medical and Dental Sciences. 2014; 3(9): 2194-207.

9. Tsuji I, Ami K, Mujazaki A, et al. Benefit of diagnostic laparoscopy for patients with unexplained infertility and normal hysterosalphingography finding. Tohaku J Exp Med. 2009; 219: 239-42.
10. Puri S, Jain D, Puri S, Kaushal S, Deol SK. Laparohysteroscopy in female infertility: A diagnostic cum therapeutic tool in Indian setting. Int J Appl Basic Med Res. 2015; 5(1): 46-8.

\footnotetext{
Sujata N Datti ${ }^{1}$, Shruthi ${ }^{2}$, Shreedhar Venkatesh ${ }^{3}$, Nagatejaswi $\mathbf{T}^{4}$, Ravi Sree Shivani ${ }^{5}$

${ }^{1}$ Professor, Department of Obstetrics and Gynaecology, VIMS and RC, Bengaluru, Karnataka, India; ${ }^{2}$ Assistant Professor, Department of Obstetrics and Gynaecology, VIMS and RC, Bengaluru, Karnataka, India; ${ }^{3}$ Professor and Head of Department, Department of Obstetrics and Gynaecology, VIMS and RC, Bengaluru, Karnataka, India; ${ }^{4}$ Post-Graduate, Department of Obstetrics and Gynaecology, VIMS and RC, Bengaluru, Karnataka, India; ${ }^{5}$ Post-Graduate, Department of Obstetrics and Gynaecology, VIMS and RC, Bengaluru, Karnataka, India.
} 